Western University

Scholarship@Western

Bone and Joint Institute

$12-31-2015$

\title{
A Trial of Wound Irrigation in the Initial Management of Open Fracture Wounds
}

\author{
Mohit Bhandari \\ Division of Orthopaedic Surgery \\ Kyle J. Jeray \\ Greenville Hospital System \\ Brad A. Petrisor \\ Division of Orthopaedic Surgery \\ P. J. Devereaux \\ Departments of Clinical Epidemiology and Biostatistics \\ Diane Heels-Ansdell \\ Departments of Clinical Epidemiology and Biostatistics
}

See next page for additional authors

Follow this and additional works at: https://ir.lib.uwo.ca/boneandjointpub

Part of the Medicine and Health Sciences Commons

\section{Citation of this paper:}

Bhandari, Mohit; Jeray, Kyle J.; Petrisor, Brad A.; Devereaux, P. J.; Heels-Ansdell, Diane; Schemitsch, Emil H.; Anglen, Jeff; Della Rocca, Gregory J.; Jones, Clifford; Kreder, Hans; Liew, Susan; McKay, Paula; Papp, Steven; Sancheti, Parag; Sprague, Sheila; Stone, Trevor B.; Sun, Xin; Tanner, Stephanie L.; Tornetta, Paul; Tufescu, Ted; Walter, Stephen; and Guyatt, Gordon H., "A Trial of Wound Irrigation in the Initial Management of Open Fracture Wounds" (2015). Bone and Joint Institute. 1059.

https://ir.lib.uwo.ca/boneandjointpub/1059 


\section{Authors}

Mohit Bhandari, Kyle J. Jeray, Brad A. Petrisor, P. J. Devereaux, Diane Heels-Ansdell, Emil H. Schemitsch, Jeff Anglen, Gregory J. Della Rocca, Clifford Jones, Hans Kreder, Susan Liew, Paula McKay, Steven Papp, Parag Sancheti, Sheila Sprague, Trevor B. Stone, Xin Sun, Stephanie L. Tanner, Paul Tornetta, Ted Tufescu, Stephen Walter, and Gordon H. Guyatt 
ORIGINAL ARTICLE

\section{A Trial of Wound Irrigation in the Initial Management of Open Fracture Wounds}

\author{
The FLOW Investigators*
}

\section{ABSTRACT}

\section{BACKGROUND}

The management of open fractures requires wound irrigation and débridement to remove contaminants, but the effectiveness of various pressures and solutions for irrigation remains controversial. We investigated the effects of castile soap versus normal saline irrigation delivered by means of high, low, or very low irrigation pressure.

\section{METHODS}

In this study with a 2-by-3 factorial design, conducted at 41 clinical centers, we randomly assigned patients who had an open fracture of an extremity to undergo irrigation with one of three irrigation pressures (high pressure [ $>20$ psi], low pressure [5 to 10 psi], or very low pressure [ 1 to 2 psi]) and one of two irrigation solutions (castile soap or normal saline). The primary end point was reoperation within 12 months after the index surgery for promotion of wound or bone healing or treatment of a wound infection.

\section{RESULTS}

A total of 2551 patients underwent randomization, of whom 2447 were deemed eligible and included in the final analyses. Reoperation occurred in 109 of 826 patients (13.2\%) in the high-pressure group, 103 of 809 (12.7\%) in the low-pressure group, and 111 of $812(13.7 \%)$ in the very-low-pressure group. Hazard ratios for the three pairwise comparisons were as follows: for low versus high pressure, 0.92 (95\% confidence interval [CI], 0.70 to $1.20 ; \mathrm{P}=0.53$ ), for high versus very low pressure, 1.02 (95\% CI, 0.78 to $1.33 ; \mathrm{P}=0.89$ ), and for low versus very low pressure, 0.93 ( $95 \%$ CI, 0.71 to $1.23 ; \mathrm{P}=0.62$ ). Reoperation occurred in 182 of 1229 patients $(14.8 \%)$ in the soap group and in 141 of $1218(11.6 \%)$ in the saline group (hazard ratio, $1.32,95 \% \mathrm{CI}, 1.06$ to $1.66 ; \mathrm{P}=0.01$ ).

\section{CONCLUSIONS}

The rates of reoperation were similar regardless of irrigation pressure, a finding that indicates that very low pressure is an acceptable, low-cost alternative for the irrigation of open fractures. The reoperation rate was higher in the soap group than in the saline group. (Funded by the Canadian Institutes of Health Research and others; FLOW ClinicalTrials.gov number, NCT00788398.)
The members of the writing committee (Mohit Bhandari, M.D., Ph.D., Kyle J. Jeray, M.D., Brad A. Petrisor, M.D., P.J. Devereaux, M.D., Ph.D., Diane Heels-Ansdell, M.Sc., Emil H. Schemitsch, M.D., Jeff Anglen, M.D., Gregory J. Della Rocca, M.D., Ph.D., Clifford Jones, M.D., Hans Kreder, M.D., M.P.H., Susan Liew, M.B., B.S., Paula McKay, B.Sc., Steven Papp, M.D., Parag Sancheti, M.B., B.S., M.Ch., D.N.B., Sheila Sprague, Ph.D., Trevor B. Stone, M.D., Xin Sun, Ph.D., Stephanie L. Tanner, M.S., Paul Tornetta III, M.D., Ted Tufescu, M.D., Stephen Walter, Ph.D., and Gordon H. Guyatt, M.D.) assume responsibility for the overall content and integrity of the article. The affiliations of the members of the writing group are listed in the Appendix. Address reprint requests to $\mathrm{Dr}$. Bhandari at the Division of Orthopaedic Surgery, McMaster University, 293 Wellington St. N., Suite 110, Hamilton, ON L8L 8E7, Canada, or at bhandam@mcmaster.ca.

*A complete list of the Fluid Lavage of Open Wounds (FLOW) Investigators is provided in the Supplementary Appendix, available at NEJM.org.

This article was published on October 8, 2015, at NEJM.org.

DOI: 10.1056/NEJMoa1508502 Copyright (๑) 2015 Massachusetts Medical Society. 
T HE INITIAL MANAGEMENT OF OPEN fractures requires thorough irrigation and débridement $^{1-4}$ to prevent infection and promote wound and bone healing. ${ }^{2,4}$ Clinicians accomplish débridement by removing all visible debris and necrotic tissue and by providing copious irrigation of the wound.

Controversy exists regarding the choice of irrigation pressure and solution..$^{4-13}$ High pressure may be more effective than low pressure in removing particulate matter and bacteria ${ }^{7-10}$ but at the expense of bone damage ${ }^{8,11}$ and a resultant delay in bone healing. ${ }^{12}$ Low pressure may avoid bone damage and delayed healing but at the possible cost of less effective removal of foreign matter and bacteria.

Regarding the preferred irrigation solution, there is a strong biologic rationale for the use of surfactants, such as soap. ${ }^{14-20}$ Because soap contains both nonpolar and polar molecules, it acts as an emulsifier, dispersing one liquid, or particulate, into another immiscible liquid. As compared with other enhanced irrigation solutions (i.e., those that contain antiseptic or antibiotic agents), soap is less expensive, ${ }^{21}$ does not have a risk of antibiotic resistance,${ }^{14}$ and is less toxic. ${ }^{1,7,17-19,22,23}$

To address these issues regarding irrigation pressures and solutions, we conducted the Fluid Lavage of Open Wounds (FLOW) trial in patients requiring surgery for open fracture. We examined the effect of alternative pressures and castile soap versus normal saline irrigation on a composite of a number of different reasons for reoperations within 12 months after the index surgery.

\section{METHODS}

\section{STUDY DESIGN}

Our study was an international, blinded, randomized, controlled trial that used a 2-by-3 factorial design to evaluate the effects of high versus low versus very low (gravity flow) irrigation pressures and soap versus normal saline solutions on reoperation rates among patients with an open fracture. The objectives and methods of the trial were published previously. ${ }^{24}$ The study was approved by the ethics committees at McMaster University, Greenville Health System, and each participating center. All the patients provided written informed consent.

\section{STUDY OVERSIGHT}

The study was funded by the Canadian Institutes of Health Research, the U.S. Department of Defense, and others. The Clinical Advances through Research and Information Translation (CLARITY) Research Group at McMaster University coordinated the trial and was responsible for the trial randomization, the maintenance, validation, and analysis of the data, and the study-center coordination. The Greenville Health System assisted in the coordination of study sites in the United States. Stryker donated Surgilav irrigators for the trial for clinical sites in Asia. Zimmer provided the Pulsavac irrigator at a reduced cost to selected clinical sites in North America. Triad Medical donated castile soap; castile soap from Aplicare was purchased at full cost. No donor or funder had a role in the design or conduct of the study, the collection or analyses of the data, or the preparation of the manuscript.

The steering committee (see the Supplementary Appendix, available with the full text of this article at NEJM.org), chaired by the principal investigators, designed the trial and prespecified the statistical analysis plan. The members of the steering committee vouch for the completeness and accuracy of the data and analyses reported and for the adherence of the trial to the protocol, available at NEJM.org. The first author, who was the chair of the writing committee, wrote the first draft of the manuscript; all the members of the writing committee made revisions and made the decision to submit the manuscript for publication.

\section{PATIENTS}

From June 2009 through September 2013, we recruited patients across 41 sites in the United States, Canada, Australia, Norway, and India. Eligible patients were 18 years of age or older with an open fracture of an extremity that required operative fixation. Extremity was defined as arm, wrist, leg, ankle, foot, clavicle, or scapula. We excluded fractures of the pelvic ring and axial skeleton and fractures of the hand (metacarpals and phalanges) and toes (phalanges). Detailed eligibility criteria are listed in the Supplementary Appendix.

\section{PROCEDURES}

Patients were stratified according to study center and Gustilo-Anderson fracture grade (I or II vs. 
III) (see the Supplementary Appendix). Patients underwent randomization in a 1:1:1:1:1:1 ratio and were assigned to one of six treatment groups: soap and very low pressure, soap and low pressure, soap and high pressure, saline and very low pressure, saline and low pressure, or saline and high pressure. Randomization was performed with the use of a central computerized system with variable block sizes, thus ensuring concealment of the study-group assignments. Patients, end-point adjudicators, and data analysts were unaware of the study-group assignments.

During surgery, the initial management of the open fracture included irrigation that was delivered by means of very low pressure (1 to $2 \mathrm{psi}$ ), low pressure (5 to $10 \mathrm{psi}$ ), or high pressure ( $>20 \mathrm{psi}$ ). In the operating room, surgeons used a sterile technique to prepare either a $0.45 \%$ solution of castile soap (Triad Medical and Aplicare) in normal saline (see the Supplementary Appendix) or used sterile normal saline alone. We standardized the perioperative antibiotic regimens and the minimum amount of solution according to the severity of the open fracture wound, which was graded according to the Gustilo-Anderson classification (3 liters for grade I fracture and 6 liters for grade II or III) (see the Supplementary Appendix). ${ }^{2}$

Patients returned for follow-up assessments at 1, 2, and 6 weeks and 3, 6, 9, and 12 months after surgery. Details of the follow-up process are provided in the Supplementary Appendix.

\section{STUDY END POINTS}

The primary end point was reoperation, defined as surgery that occurred within 12 months after the initial procedure to treat an infection at the operative site or contiguous to it, manage a wound-healing problem, or promote bone healing. The procedures included in this composite end point were the following: irrigation and débridement for an infected wound; revision and closure for wound dehiscence; wound coverage for an infected or necrotic wound; drainage of a hematoma; reoperation for hardware failure that was probably related to an infection, woundhealing problem, or bone-healing problem (e.g., delayed union or nonunion); bone grafting or implant-exchange procedure for established nonunion in patients with a postoperative fracture gap of less than $1 \mathrm{~cm}$; intramedullary nail dy- namizations in the operating room (dynamization involves removal of locking screws from the intramedullary nail to allow fracture ends to compress with weight bearing); fasciotomies for the compartment syndrome; and other events as determined by the adjudication committee. Full details are provided in the Supplementary Appendix. Secondary end points included nonoperatively managed infection and wound-healing and bone-healing problems within 12 months after the index surgery.

A central adjudication committee, whose members were unaware of the study-group assignments, adjudicated all primary and key secondary end points. To minimize random error, the committee blindly adjudicated trial eligibility on the basis of data available before or shortly after randomization (see the Supplementary Appendix). ${ }^{25}$

\section{STATISTICAL ANALYSIS}

We originally calculated that the sample size would have to be 2280 patients, with 1140 patients per solution group and 760 patients per pressure group. This sample size was based on the size of the irrigation-pressure groups and was calculated to ensure that the study would have a power of $80 \%$ to identify differences among the three irrigation-pressure groups in effects of pairwise comparisons at an adjusted alpha level of 0.0188 , on the basis of a rate of reoperation within 12 months of $30 \%$ in a control group and a $25 \%$ lower relative risk with one irrigation pressure than with another. We estimated a similar controlgroup reoperation rate for normal saline,,$^{13,26,27}$ and the study therefore also had $98 \%$ power to detect a $25 \%$ lower relative risk with soap - a treatment effect that was endorsed by $80 \%$ of surgeons in our international survey as important enough to change practice. ${ }^{13}$

An interim analysis was performed in January 2013 after 2079 patients had been enrolled; 789 of these patients had 12-month outcomes available. The external data and safety monitoring committee considered the O'Brien-Fleming stopping criterion that specifies a significance level that maintains the overall type I error rate of $0.05,{ }^{28}$ and the committee recommended the recruitment of additional patients in the trial to account for a projected $10 \%$ loss to follow-up. We recruited a total of 2551 patients.

The analyses included all the patients in the groups to which they were randomly assigned. 
For patients for whom 12-month follow-up information was unavailable, data were included to the date of their last documented follow-up and were censored at that time. The CLARITY Research Group data analyst remained unaware of the treatment-group assignments while conducting the primary analyses.

Using Cox regression stratified according to fracture grade (I or II vs. III) and study center, we first conducted a time-to-event analysis of the main effects with respect to solution and pressure and the interaction between the two with regard to the reoperation rate. If the interaction was significant, we planned to explore the nature of the effect modification.

Our primary analysis was a Cox regression stratified according to the severity of the open fracture $^{2}$ and study center, with reoperation as the end point in the time-to-event analysis. The Cox regression to investigate the effect of irrigation pressure was also stratified according to irrigation solution. Similarly, the irrigation-solution analysis was stratified according to irrigation pressure. We also performed analyses, using Cox regression, that were adjusted for age, injury (upper extremity vs. lower extremity), fracture gap ( $<1 \mathrm{~cm}$ vs. $\geq 1 \mathrm{~cm}$ ), type of internal fixation (intramedullary nail, external fixator, plate, other internal fixation, other fixation, or none), and severity of wound contamination (mild vs. moderate vs. severe). For both the primary and adjusted analyses, we tested the proportional-hazards assumption.

We examined the three-category randomized pressure variable for statistical significance at an alpha level of 0.05 ; if the results were significant, we planned to conduct pairwise comparisons using an alpha level of 0.0188 . In instances of significant differences between results, we conducted a sensitivity analysis that was based on plausible differences in event rates among patients lost to follow-up versus those for whom follow-up was complete..$^{29}$ In this case, we tested the effect of assuming that in the saline group, the event rate among patients who were lost to follow-up would be twice as high as the rate among those successfully followed. All the analyses were performed with the use of SAS software, version 9.2 (SAS Institute).

Before unblinding and as described in our statistical analysis plan, we prespecified 12 subgroup analyses that explored a possible modification of the effect of alternative irrigation pressures and solutions in subgroups defined according to fracture severity, location of fracture (upper vs. lower extremity, tibial vs. nontibial fracture, and intraarticular vs. extraarticular involvement), and aspects of the surgical wound débridement. We conducted an additional post hoc subgroup analysis that evaluated the possible effect modification according to time to surgery ( $<6$ hours, 6 to 12 hours, or $>12$ hours after injury). We used multiple criteria to consider the credibility of any possible subgroup effects. ${ }^{30}$ The Supplementary Appendix provides details regarding hypothesized subgroup effects.

We first interpreted the results on the basis of a blinded review of the results of our primary analysis. ${ }^{31}$ The randomization code was then broken, the correct interpretation chosen, and the draft of the manuscript was written. The Supplementary Appendix provides details regarding specific analyses and our blinded interpretation.

\section{RESULTS}

\section{PATIENTS}

From June 2009 through September 2013, we randomly assigned 859 of 2551 enrolled patients to the high-pressure group, 846 to the lowpressure group, and 846 to the very-low-pressure group. A total of 1275 patients were assigned to irrigation with soap and 1276 to irrigation with normal saline. Of 2551 patients enrolled, the adjudication committee (whose members were unaware of the treatment assignments) determined that 104 patients were ineligible owing to no receipt of surgical treatment (47 patients), incorrect fracture type (48), history of osteomyelitis (1), retained hardware from a previous fracture in the same extremity (2), use of immunosuppressive medication (2), or age (4). The remaining 2447 patients were included in the final analyses, with the patients' data analyzed in the treatment groups to which the patients had been randomly assigned. We obtained 12-month follow-up data for $90 \%$ of the patients (Figs. S1 and S2 in the Supplementary Appendix).

The majority of patients were men, were in their 40s, were those with a lower-extremity fracture, and were those with no concomitant major trauma. The most common mechanism of injury was motor vehicle accident. The characteristics were similar in the randomized study groups (Table 1). Typical patients underwent plate fixation, underwent their first irrigation 
within 10 hours after their injury, and received antibiotic prophylaxis; the treatments, including volumes of irrigation solutions, were similar in the randomized study groups (Table 1 , and Tables S1 and S2 in the Supplementary Appendix).

\section{ADHERENCE TO ASSIGNED INTERVENTION}

Adherence by the surgeon to the initially assigned irrigation pressure ranged from $96.5 \%$ to $98.8 \%$. Adherence by the surgeon to the initially assigned irrigation solution was $97.9 \%$ in the soap group and $99.6 \%$ in the saline group (Tables S3 and S4 in the Supplementary Appendix).

\section{INTERACTION BETWEEN IRRIGATION PRESSURES AND SOLUTIONS}

Results showed no interaction between solution and pressure $(\mathrm{P}=0.31)$. Therefore, we completed separate analyses for irrigation pressures and solutions.

\section{PRIMARY END POINT}

According to Irrigation Pressure

A primary study end-point event, reoperation within 12 months after the index procedure in order to treat an infection, manage a woundhealing problem, or promote bone healing, occurred in 323 of the 2447 patients (13.2\%). The rate of the primary end point did not differ significantly according to type of irrigation pressure: 109 of 826 patients (13.2\%) in the highpressure group had a primary end-point event, as did 103 of 809 patients $(12.7 \%)$ in the lowpressure group and 111 of 812 (13.7\%) in the very-low-pressure group $(\mathrm{P}=0.80$ for the threeway comparison). Hazard ratios were as follows: for low pressure versus high pressure, 0.92 ( $95 \%$ confidence interval [CI], 0.70 to $1.20 ; \mathrm{P}=0.53$ ); for high pressure versus very low pressure, 1.02 (95\% CI, 0.78 to 1.33; $\mathrm{P}=0.89$ ); and for low pressure versus very low pressure, 0.93 ( $95 \%$ CI, 0.71 to $1.23 ; \mathrm{P}=0.62$ ) (Table 2 and Fig. $1 \mathrm{~A}$ ). Adjusted analyses yielded similar results (Table $\mathrm{S} 5$ in the Supplementary Appendix).

\section{According to Irrigation Solution}

The rate of the primary end point differed significantly according to type of irrigation solution: 182 of 1229 patients (14.8\%) in the soap group had a primary end-point event, as compared with 141 of $1218(11.6 \%)$ in the saline group (hazard ratio in the soap group, 1.32; 95\% CI: 1.06 to 1.66; $\mathrm{P}=0.01$ ) (Table 3 and Fig. 1B). Adjusted analyses yielded similar results for the effect of solution (Table S6 in the Supplementary Appendix).

The frequency of all components of the primary end point was higher in the soap group than in the saline group. The frequency of implant-exchange procedures for established nonunion in patients with a fracture gap of less than $1 \mathrm{~cm}$ was significantly higher in the soap group than in the saline group (hazard ratio, 1.59; 95\% CI, 1.01 to 2.51; $\mathrm{P}=0.046$ ) (Table 3). Our sensitivity analysis showed that if we assumed that the patients who were lost to follow-up in the soap group had the same risk of the primary end point as those who had complete follow-up and that the patients who were lost to follow-up in the saline group had a risk of the primary end point that was twice as high as the risk among those with complete follow-up, then the study would lose statistical significance of the effect of soap versus saline $(\mathrm{P}=0.16)$.

\section{SECONDARY END POINTS}

We found no significant differences among the three irrigation pressures with respect to the secondary end points of nonoperatively managed infection, wound-healing problem, and bonehealing problem (Table 2). Likewise, we found no significant differences between the two irrigation solutions with respect to any of the secondary end points (Table 3).

\section{SUBGROUP ANALYSES}

Subgroup analyses of the various irrigation pressures and solutions yielded results that were consistent with the primary treatment effects for each intervention. The exceptions were tibial versus nontibial fracture, for which the results suggested a trend toward superiority of very low pressure over low or high pressure in patients with a tibial fracture, and a similarity in the soap group and the saline group when the duration of antibiotic use after surgery was 4 days or more (Fig. 2, and Tables S7 and S8 in the Supplementary Appendix).

\section{DISCUSSION}

We found no significant influence of irrigation pressure on our composite primary end point of various forms of reoperation for treatment of infection, wound-healing problem, or bone-healing problem within 12 months after the initial surgery. The irrigation of open fracture wounds 


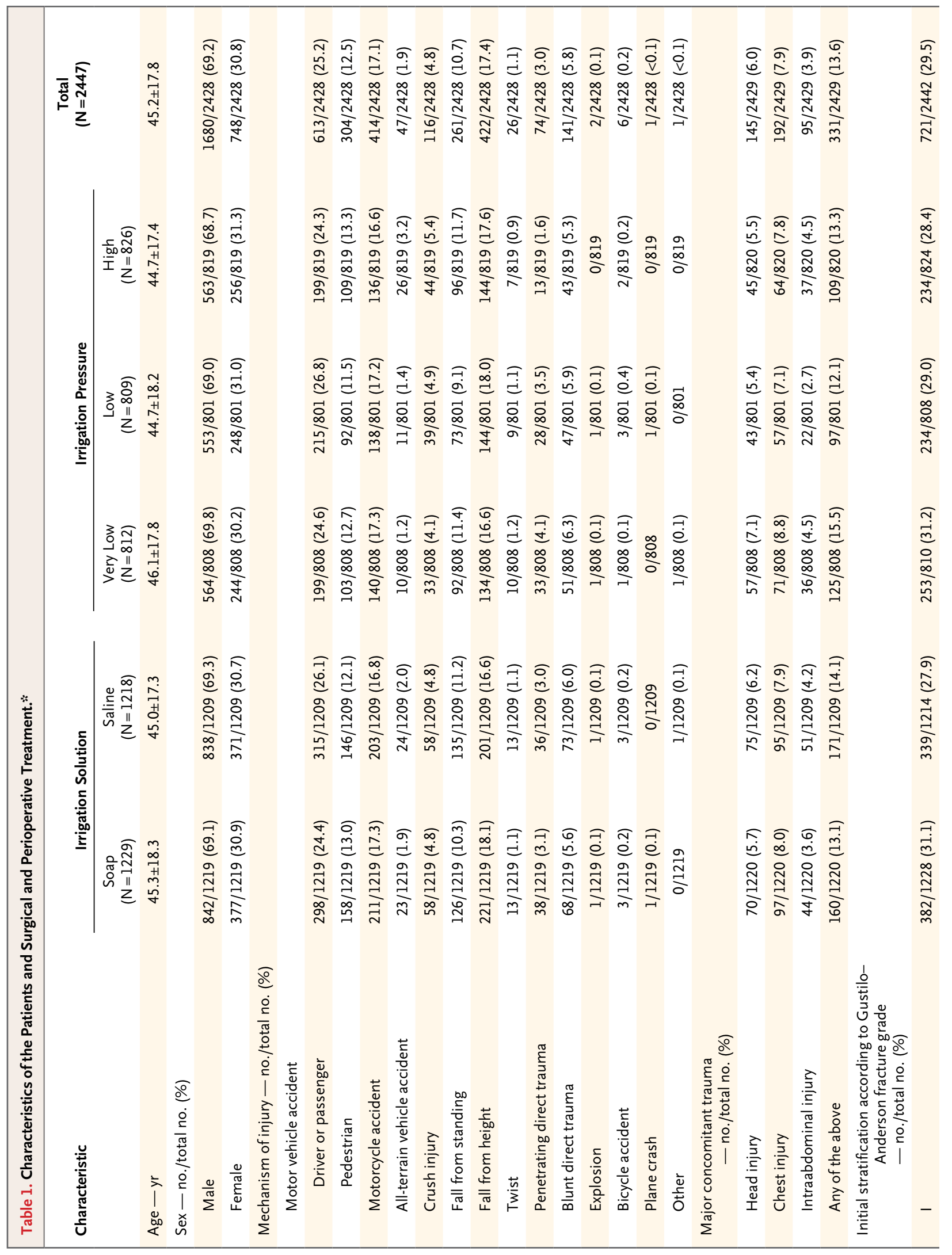




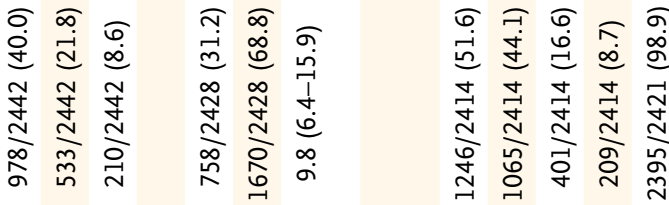

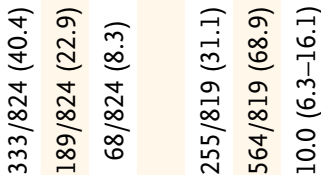

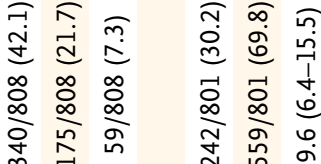

ส ส ส $ส$ ส

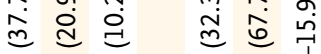

일

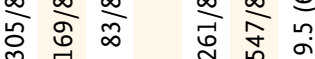

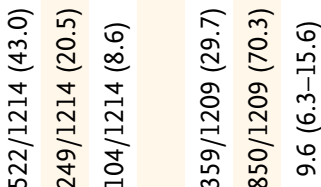

크

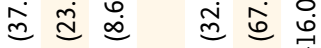

ஸิ

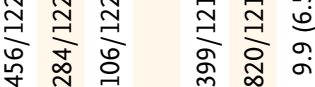

$\approx \tilde{m} \sigma \widehat{\sigma} \sigma$

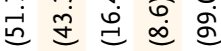

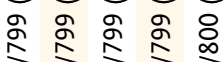

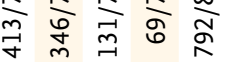

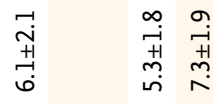

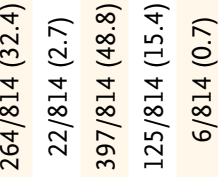

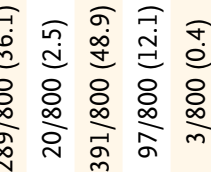

ส ส $ส$ อ

눈 守

రొ

ஓे 它

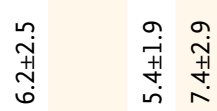

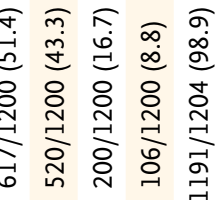

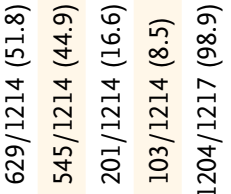

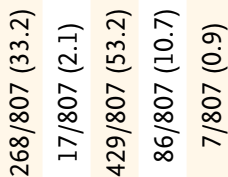

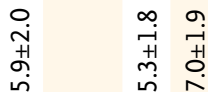

กิ กิ วิ

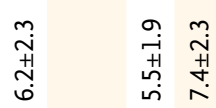

กิ $\infty$

$\stackrel{m}{m} \stackrel{\infty}{\mathfrak{d}}$ :

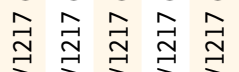

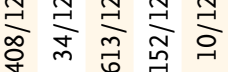

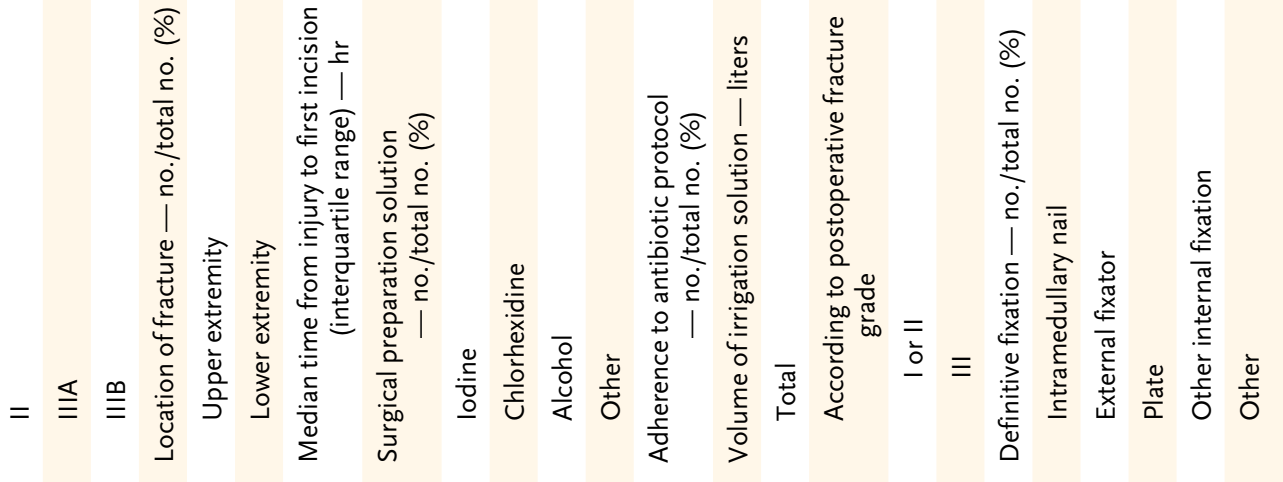

The New England Journal of Medicine 


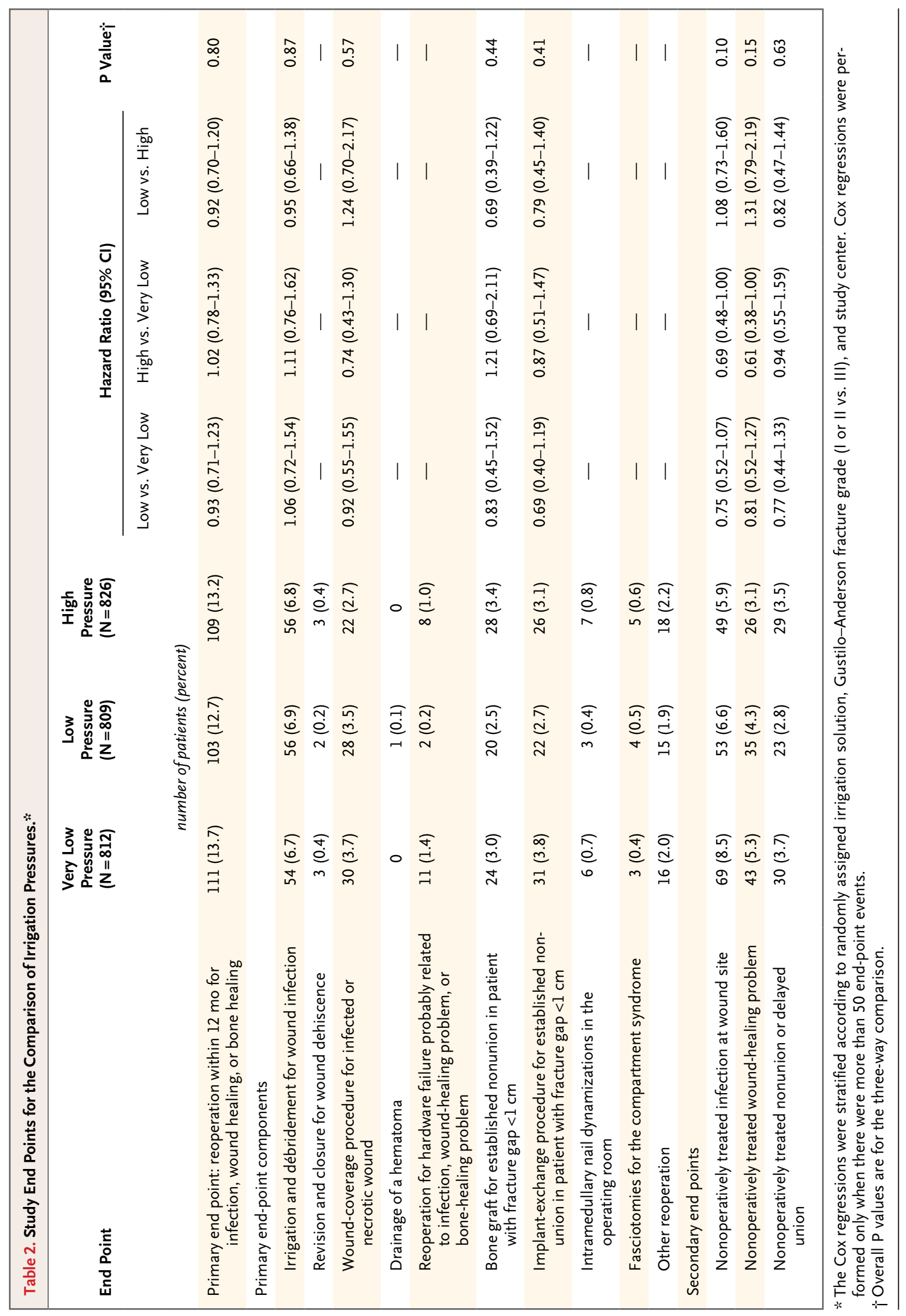


with soap, as compared with saline solution, was associated with a significantly higher rate of reoperation within 12 months. The effects of the irrigation pressures and solutions were consistent across all components of the primary end point. No significant differences in the rates of secondary end points (nonoperatively managed infection, wound-healing problem, and bonehealing problem) were observed between the two irrigation solutions or among the three irrigation pressures.

A possible effect modification was observed in two subgroups: subgroup analyses suggested that very low pressure was superior to low or high pressure in patients with a tibial fracture but inferior in patients with other fractures $(\mathrm{P}=0.05$ for interaction) and that saline solution was superior to soap when antibiotics were given for less than 4 days after surgery, but saline and soap were similar when antibiotics were given for 4 or more days ( $\mathrm{P}=0.03$ for interaction). Because many subgroup analyses were performed, the positive results in these two subgroups have relatively low credibility. ${ }^{30}$

Our study had several strengths. We included safeguards against potential bias (concealed randomization and concealment of study-group assignments from patients, end-point adjudicators, and data analysts) and safeguards against interpretation bias. ${ }^{31}$ The study also had broad inclusion criteria with a large number of centers in countries with diverse health care systems, as well as a focus on an end point (i.e., reoperation) that is of unequivocal importance to both patients and the health care system.

Our study has certain limitations. Although the surgeons had high adherence to the initial irrigation protocol during the index surgery, the rate of surgeons' adherence to the originally assigned pressure and solution for the 615 patients who required a secondary operative irrigation and débridement decreased to $75.9 \%$ for irrigation pressure and $79.3 \%$ for irrigation solution. This level of adherence is still relatively high, and we found a detrimental effect of soap that any intervention crossover would tend to obscure.

Our estimates of the treatment effect of high versus low pressure, high versus very low pressure, and low versus very low pressure, although close to 1.0, exclude large differences but do not exclude small but potentially important differences. For instance, on the basis of the $95 \%$

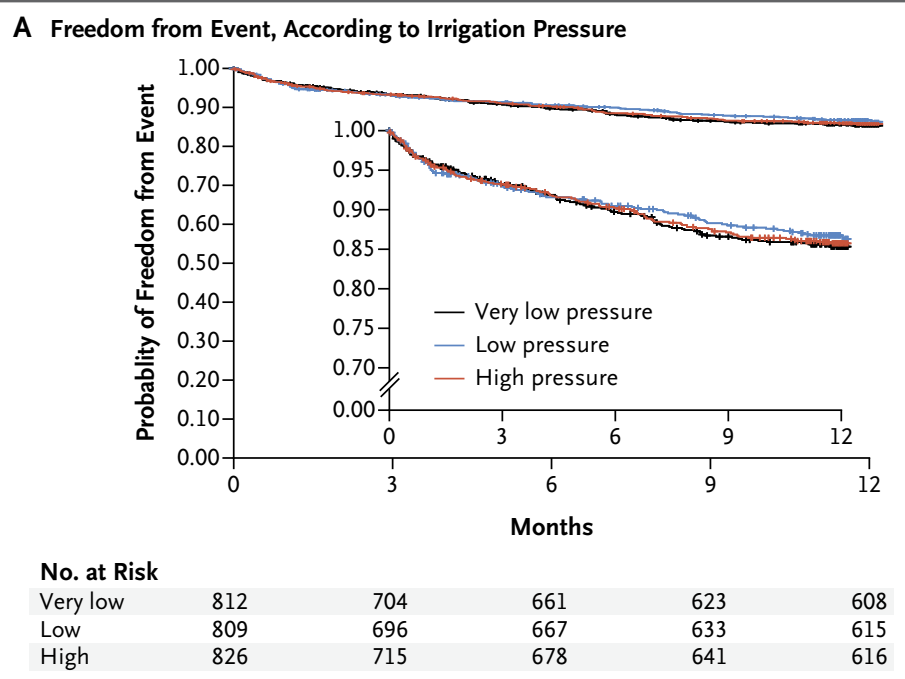

B Freedom from Event, According to Irrigation Solution

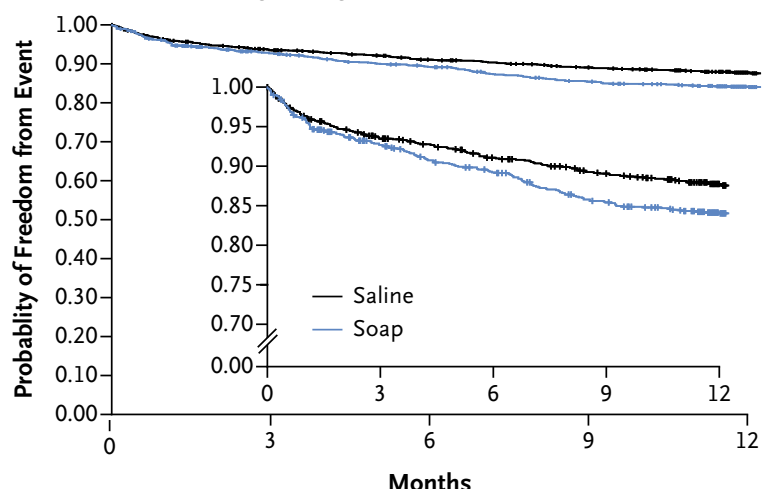

No. at Risk

Soap

Saline

1229

1218

1055

995

936

905

Figure 1. Kaplan-Meier Estimates of Freedom from the Primary End Point. Panel A shows the Kaplan-Meier estimates of the probability of freedom from the primary end point (reoperation within 12 months after the index surgery) according to irrigation pressure (very low pressure, 1 to 2 psi; low pressure, 5 to $10 \mathrm{psi}$; or high pressure, $>20 \mathrm{psi}$ ). Tick marks indicate censored data. The number at risk reported at 12 months includes patients whose 12 -month visit was completed between 11 months and 12 months. Clinical sites were permitted to complete the 12 -month visit between 11 months and 12 months, provided that the patient's wound and fracture had previously been deemed to be healed and that the patient would not be returning for any further clinical assessment. Panel B shows the Kaplan-Meier estimates of the probability of freedom from the primary end point according to irrigation solution. In each panel, the inset shows the same data on an enlarged $y$ axis.

confidence intervals, our results are consistent with high-pressure irrigation resulting in either $22 \%$ fewer operations or $33 \%$ more operations as compared with very low pressure.

A total of $10 \%$ of the patients who underwent 


\begin{tabular}{|c|c|c|c|c|}
\hline \multirow[t]{2}{*}{ End Point } & $\begin{array}{l}\text { Soap } \\
(N=1229)\end{array}$ & $\begin{array}{c}\text { Saline } \\
(\mathrm{N}=1218)\end{array}$ & $\begin{array}{l}\text { Hazard Ratio } \\
(95 \% \mathrm{CI})\end{array}$ & P Value \\
\hline & \multicolumn{4}{|c|}{ number of patients (percent) } \\
\hline $\begin{array}{l}\text { Primary end point: reoperation within } 12 \text { mo for infection, wound healing, } \\
\text { or bone healing }\end{array}$ & $182(14.8)$ & $141(11.6)$ & $1.32(1.06-1.66)$ & 0.01 \\
\hline \multicolumn{5}{|l|}{ Primary end-point components } \\
\hline Irrigation and débridement for wound infection & $87(7.1)$ & $79(6.5)$ & $1.11(0.81-1.51)$ & 0.53 \\
\hline Revision and closure for wound dehiscence & $8(0.7)$ & 0 & - & - \\
\hline Wound-coverage procedure for infected or necrotic wound & $45(3.7)$ & $35(2.9)$ & $1.33(0.85-2.08)$ & 0.22 \\
\hline Drainage of hematoma & $1(0.1)$ & 0 & - & - \\
\hline $\begin{array}{l}\text { Reoperation for hardware failure probably related to infection, wound- } \\
\text { healing problem, or bone-healing problem }\end{array}$ & $11(0.9)$ & $10(0.8)$ & - & - \\
\hline Bone graft for established nonunion in patient with fracture gap $<1 \mathrm{~cm}$ & $39(3.2)$ & $33(2.7)$ & $1.25(0.78-2.01)$ & 0.35 \\
\hline $\begin{array}{l}\text { Implant-exchange procedure for established nonunion in patient with } \\
\text { fracture gap }<l \mathrm{~cm}\end{array}$ & $48(3.9)$ & $31(2.5)$ & $1.59(1.01-2.51)$ & 0.046 \\
\hline Intramedullary nail dynamizations in the operating room & $8(0.7)$ & $8(0.7)$ & - & - \\
\hline Fasciotomies for the compartment syndrome & $7(0.6)$ & $5(0.4)$ & - & - \\
\hline Other & $25(2.0)$ & $24(2.0)$ & - & - \\
\hline \multicolumn{5}{|l|}{ Secondary end points } \\
\hline Nonoperatively treated infection at wound site & $82(6.7)$ & $89(7.3)$ & $0.97(0.71-1.31)$ & 0.82 \\
\hline Nonoperatively treated wound-healing problem & $51(4.1)$ & $53(4.4)$ & $0.97(0.65-1.43)$ & 0.86 \\
\hline Nonoperatively treated nonunion or delayed union & $41(3.3)$ & $41(3.4)$ & $1.02(0.65-1.58)$ & 0.94 \\
\hline
\end{tabular}

* The Cox regressions were stratified according to randomly assigned irrigation pressure, Gustilo-Anderson fracture grade (I or II vs. III), and study center. Cox regressions were performed only when there were more than 50 end-point events.

randomization were not followed to 12 months; the survival analysis included available data for these patients. The finding of the superiority of saline to soap was not robust to a sensitivity analysis that assumed that patients in the saline group who were lost to follow-up had a risk of event that was twice as high as the risk among those with complete follow-up. This analysis reduces our strength of inference that soap is inferior, but it does not undermine the conclusion that soap is no better than saline. The use of a single concentration of soap solution limited our ability to explore a potentially efficacious dose. It is plausible that the soap-solution concentration $(0.45 \%)$ was too high and that a lower concentration might have been effective. Our choice of castile soap and dosing was, however, based on a large body of experimental evidence, ${ }^{714-19}$ a recent clinical trial that used this formulation ${ }^{21}$ without adverse effects, and our pilot study, which suggested its safety. ${ }^{27}$

Our trial defined the highest pressure category as 20 psi or higher, whereas prior experimental studies have used pressures of more than 50 psi.
Our cutoff points for pressure were based on a prior survey of surgeons and on the American College of Surgeons definition of high pressure as 15 to 35 psi and low pressure as 1 to 15 psi. We further subcategorized the low-pressure category to low (5 to 10 psi) and very low (1 to 2 psi), given the available settings on the handheld, battery-operated irrigators in this trial.

A prior randomized trial addressed the relative effect of irrigation pressures on patient-important outcomes. ${ }^{32}$ That trial, which involved 335 patients who presented to the emergency department with open wounds within 24 hours after injury, compared pressures of 13 psi (intermediate between our low and high pressures) with very low pressure (1 to 2 psi) administered with a bulb syringe. The authors found a significantly lower rate of wound infection with the higher pressure $(1.3 \%$ vs. $6.9 \%, \mathrm{P}=0.02)$. That study did not conceal randomization assignments, did not blind the assessment of infections, and had a high loss to follow-up (19\% of patients). The methodologic differences between that study and ours may explain the differences in outcomes. 


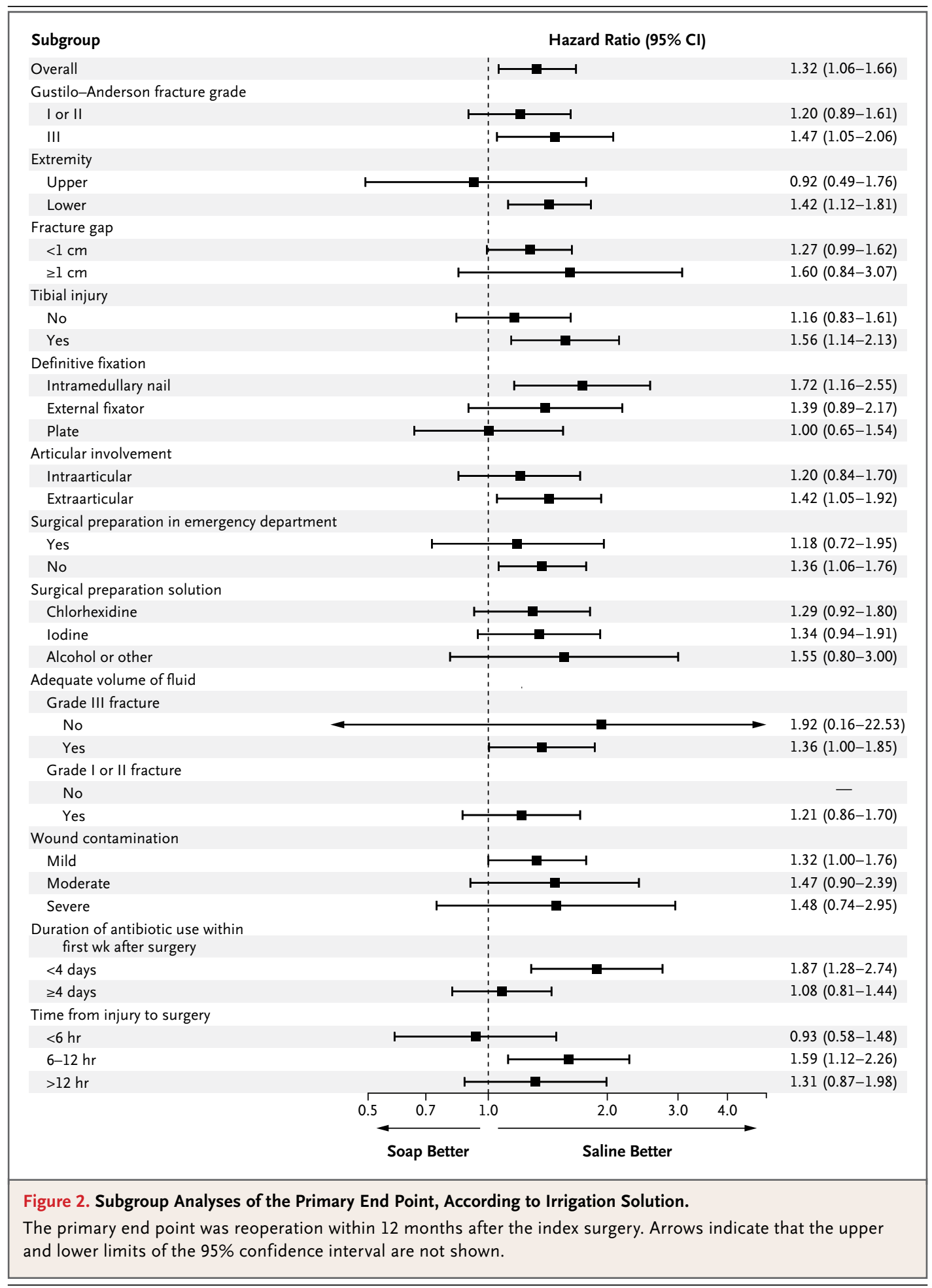

Our results challenge the results of prior lines recommend high-pressure irrigation. ${ }^{33-35}$ studies, guidelines, and a large body of experi- Although surgical and orthopedic organizations mental evidence that have favored higher pres- do not provide guidance on irrigation pressures, sures (typically $>20$ psi) for the effective removal several expert authors suggest the use of irrigaof contaminants. A number of nursing guide- tion pressures between 8 and 12 psi.,

The New England Journal of Medicine 
Experimental evidence has suggested that irrigation pressures of less than 10 psi are ineffective in removing soil contaminants from contaminated open wounds. ${ }^{5}$ Experimental studies have also shown that high-pressure irrigation is more effective than low-pressure irrigation in the removal of bacteria, especially when the time to irrigation was delayed beyond 6 hours. ${ }^{36}$ In contrast, some experimental studies have shown complications from high-pressure irrigation, including increased damage to fractured bone, ${ }^{37}$ bacterial propagation into soft tissues and the intramedullary canal of the fractured bone, ${ }^{11,37}$ promotion of stem-cell differentiation from bone-forming cells (osteoblasts) toward the adipocyte cell type, ${ }^{38}$ and impairment of in vivo fracture healing. ${ }^{12}$ Our results suggest that findings from experimental studies do not always translate into differences in patient-important outcomes in clinical practice.

With regard to irrigation solutions, our findings contrast with those of prior experimental studies $^{1-7,14-21,27}$ in laboratory and animal models that showed soap solution to be more effective than normal saline in removing bacteria and particulate matter from wounds and bone, ,14,16,17 without toxic effects to soft tissues and bone. ${ }^{7}$ One trial involving 400 patients showed that, at a mean follow-up of 1.3 years, a $0.45 \%$ soap solution was associated with a lower risk of infection than the risk with an antibiotic solution $(100,000 \mathrm{U}$ of bacitracin per 3 liters of normal saline) (13\% vs. $18 \%$; relative risk, $0.74 ; 95 \% \mathrm{CI}$, 0.45 to 1.26$),{ }^{21}$ and a lower risk of wound-healing complications ( $4 \%$ vs. $10 \%, \mathrm{P}=0.03$ ). That trial, however, had unblinded outcome adjudication and appeared to have unconcealed randomization; there was also bias in that soap was compared with normal saline that contained antibiotics. The point estimate from our randomized FLOW pilot trial, which involved 111 patients, also favored the soap solution over normal saline (hazard ratio, $0.77 ; 95 \% \mathrm{CI}, 0.35$ to 1.69 ). ${ }^{27}$

Some experimental data support the results of our clinical trial. In an established animal model of a contaminated complex musculoskel- etal wound, the initial reduction in pseudomonas bacterial counts was greater when wound irrigation was performed with castile soap than when it was performed with normal saline (with counts reduced to $13 \%$ vs. $29 \%$ of the pretreatment level), ${ }^{39}$ but at 48 hours, bacterial counts in the soap group increased to $120 \%$ of the pretreatment levels, whereas the bacterial counts with normal saline solution were $68 \%$ of the pretreatment levels. Similarly, investigators using a Staphylococcus aureus-contaminated rat-femur model have suggested that host-tissue toxicity and necrosis from antibacterial solutions allow bacteria to thrive and bacterial levels to rebound to pretreatment levels. ${ }^{40}$

Our study may have implications for the care of patients with open fractures worldwide and may inform protocols for the management of wound irrigation for paramedics, nurses, emergency physicians, and surgeons caring for patients with open fractures. Our findings may be particularly relevant for low-income and middleincome countries, in which $90 \%$ of the road traffic fatalities globally, and probably a similar percentage of open fractures, occur..$^{41}$ In such contexts, the knowledge that there is no benefit to the use of irrigation-pressure devices can guide the allocation of limited resources - a result that is also very important for the management of open fractures in combat settings.

In conclusion, our results suggest similar reoperation rates regardless of irrigation pressure and establish very low pressure as an acceptable, low-cost alternative in the irrigation of open fractures. Our findings indicate that saline was superior to castile soap solution for the routine irrigation of acute open fractures.

\footnotetext{
The views expressed in this article are those of the authors and are not necessarily endorsed by the Department of Defense.

Supported by research grants from the Canadian Institutes of Health Research (MCT-93173), the U.S. Army Institute of Surgical Research Orthopedic Trauma Research Program (W81XWH -08-1-0473), U.S. Army Institute of Surgical Research Peer Reviewed Orthopedic Research Program (W81XWH-12-1-0530), and Association Internationale pour l'Ostéosynthèse Dynamique.

Disclosure forms provided by the authors are available with the full text of this article at NEJM.org.
}

APPENDIX

The affiliations of the members of the writing group are as follows: Division of Orthopaedic Surgery, the Department of Surgery (M.B., B.A.P., S.S.), the Departments of Clinical Epidemiology and Biostatistics (M.B., P.J.D., D.H.-A., P.M., S.S., S.W., G.H.G.) and Medicine (P.J.D., G.H.G.), and the Population Health Research Institute (P.J.D.), McMaster University, Hamilton, ON, the Division of Orthopaedic Surgery (H.K., E.H.S.) and Health Policy Management and Evaluation (H.K.), University of Toronto, and Sunnybrook Health Sciences Centre (H.K.), Toronto, the Division of Orthopaedic Surgery, University of Ottawa, Ottawa, ON (S.P.), the Department of Orthopaedics, Faculty of Medicine, University of British Columbia, Vancouver (T.B.S.), and the Department of Surgery, University of Manitoba, Winnipeg (T.T.) - all in Canada; the Department of Orthopedic Surgery, Greenville Health System, Greenville, SC (K.J.J., S.L.T.); the Department of Orthopedic Surgery, Indiana University, Indianapolis (J.A.); the Department of Orthopedic Surgery, University of 
Missouri School of Medicine, Columbia (G.J.D.R.); Center for Orthopedic Research and Education Institute, Phoenix, AZ (C.J.); the Department of Surgery, Monash University, Melbourne, VIC, Australia (S.L.); Sancheti Institute for Orthopedics and Rehabilitation, Pune, India (P.S.); Chinese Evidence-based Medicine Center, Sichuan University, Chengdu, China (X.S); and the Department of Orthopedic Surgery, Boston University School of Medicine, Boston (P.T.).

\section{REFERENCES}

1. Anglen JO. Wound irrigation in musculoskeletal injury. J Am Acad Orthop Surg 2001;9:219-26.

2. Gustilo RB, Merkow RL, Templeman D. The management of open fractures. J Bone Joint Surg Am 1990;72:299-304.

3. Foote CJ, Guyatt GH, Vignesh $\mathrm{KN}$, et al. Which surgical treatment for open tibial shaft fractures results in the fewest reoperations? A network meta-analysis. Clin Orthop Relat Res 2015;473:217992.

4. Mundi R, Chaudhry H, Niroopan G, Petrisor B, Bhandari M. Open tibial fractures: updated guidelines for management. JBJS Rev 2015;3(2):e1.

5. Barnes S, Spencer M, Graham D, Johnson HB. Surgical wound irrigation: a call for evidence-based standardization of practice. Am J Infect Control 2014;42:525-9.

6. Crowley DJ, Kanakaris NK, Giannoudis PV. Irrigation of the wounds in open fractures. J Bone Joint Surg Br 2007;89: 580-5.

7. Bhandari M, Adili A, Schemitsch EH. The efficacy of low-pressure lavage with different irrigating solutions to remove adherent bacteria from bone. J Bone Joint Surg Am 2001;83-A:412-9.

8. Bhandari M, Schemitsch EH, Adili A, Lachowski RJ, Shaughnessy SG. High and low pressure pulsatile lavage of contaminated tibial fractures: an in vitro study of bacterial adherence and bone damage. J Orthop Trauma 1999;13:526-33.

9. Gross A, Bhaskar SN, Cutright DE, Beasley JD III, Perez B. The effect of pulsating water jet lavage on experimenta contaminated wounds. J Oral Surg 1971; 29:187-90.

10. Bhhaskar SN, Cutright DE, Runsuck EE, Gross A. Pulsating water jet devices in debridement of combat wounds. Mil Med 1971;136:264-6.

11. Hassinger SM, Harding G, Wongworawat MD. High-pressure pulsatile lavage propagates bacteria into soft tissue. Clin Orthop Relat Res 2005;439:27-31.

12. Polzin B, Ellis T, Dirschl DR. Effects of varying pulsatile lavage pressure on cancellous bone structure and fracture healing. J Orthop Trauma 2006;20:261-6. 13. Petrisor B, Jeray K, Schemitsch E, et al. Fluid lavage in patients with open fracture wounds (FLOW): an international survey of 984 surgeons. BMC Musculoskelet Disord 2008;9:7.

14. Anglen JO, Apostoles S, Christensen G, Gainor B. The efficacy of various irrigation solutions in removing slime-producing staphylococcus. J Orthop Trauma 1994;8:390-6.

15. Anglen JO, Gainor BJ, Simpson WA Christensen G. The use of detergent irri- gation for musculoskeletal wounds. Int Orthop 2003;27:40-6.

16. Burd T, Christensen GD, Anglen JO, Gainor BJ, Conroy BP, Simpson WA. Sequential irrigation with common detergents: a promising new method for decontaminating orthopedic wounds. Am J Orthop (Belle Mead NJ) 1999;28:156-60. 17. Conroy BP, Anglen JO, Simpson WA, et al. Comparison of castile soap, benzalkonium chloride, and bacitracin as irrigation solutions for complex contaminated orthopaedic wounds. J Orthop Trauma 1999; 13:332-7.

18. Gainor BJ, Hockman DE, Anglen JO, Christensen G, Simpson WA. Benzalkonium chloride: a potential disinfecting irrigation solution. J Orthop Trauma 1997; 11:121-5.

19. Tarbox BB, Conroy BP, Malicky ES, et al. Benzalkonium chloride: a potential disinfecting irrigation solution for orthopaedic wounds. Clin Orthop Relat Res 1998;(346):255-61.

20. Huyette DR, Simpson WA, Walsh R, et al. Eradication by surfactant irrigation of Staphylococcus aureus from infected complex wounds. Clin Orthop Relat Res 2004;427:28-36

21. Anglen JO. Comparison of soap and antibiotic solutions for irrigation of lower-limb open fracture wounds: a prospective, randomized study. J Bone Joint Surg Am 2005;87:1415-22.

22. Kaysinger KK, Nicholson NC, Ramp WK, Kellam JF. Toxic effects of wound irrigation solutions on cultured tibiae and osteoblasts. J Orthop Trauma 1995;9:303-11. 23. Sprung J, Schedewie HK, Kampine JP. Intraoperative anaphylactic shock after bacitracin irrigation. Anesth Analg 1990; 71:430-3.

24. FLOW Investigators. Fluid Lavage of Open Wounds (FLOW): design and rationale for a large, multicenter collaborative $2 \times 3$ factorial trial of irrigating pressures and solutions in patients with open fractures. BMC Musculoskelet Disord 2010; 11:85.

25. Fergusson D, Aaron S, Guyatt GH, Hebert P. Post-randomization exclusion of patients enrolled in clinical trials: the intention-to-treat principle does not necessitate that all patients be analyzed. BMJ 2002;325:652-4.

26. Bhandari M, Guyatt G, Tornetta P III, et al. Randomized trial of reamed and unreamed intramedullary nailing of tibial shaft fractures. J Bone Joint Surg Am 2008; 90:2567-78.

27. Petrisor B, Sun $X$, Bhandari $M$, et al. Fluid Lavage of Open Wounds (FLOW): a multicenter, blinded, factorial pilot trial comparing alternative irrigating solutions and pressures in patients with open fractures. J Trauma 2011;71:596-606.

28. Pocock SJ. Clinical trials: a practical approach. Toronto: John Wiley, 1984.

29. Akl EA, Briel M, You JJ, et al. Potential impact on estimated treatment effects of information lost to follow-up in randomised controlled trials (LOST-IT): systematic review. BMJ 2012;344:e2809.

30. Sun $X$, Briel M, Walter SD, Guyatt GH. Is a subgroup effect believable? Updating criteria to evaluate the credibility of subgroup analyses. BMJ 2010;340:c117.

31. Järvinen TL, Sihvonen R, Bhandari M, et al. Blinded interpretation of study results can feasibly and effectively diminish interpretation bias. J Clin Epidemiol 2014; 67:769-72.

32. Longmire AW, Broom LA, Burch J. Wound infection following high-pressure syringe and needle irrigation. Am J Emerg Med 1987;5:179-81.

33. Storer A, Lindauer C, Proehl J, et al. Clinical practice guideline: wound preparation, 2011 (https://www.ena.org/practice -research/research/CPG/Documents/ WoundPreparationCPG.pdf).

34. Ackley BJ, Ladwig GB, Swan BA, Tucker SJ. Evidence-based nursing care guidelines: medical-surgical interventions. St. Louis: Mosby Elsevier, 2007:954.

35. Fernandez R, Griffiths R, Ussia C. Effectiveness of solutions, techniques and pressure in wound cleansing. JBI Reports 2004;2:231-70.

36. Bhandari $M$, Thompson $\mathrm{K}$, Adili A, Shaughnessy SG. High and low pressure irrigation in contaminated wounds with exposed bone. Int J Surg Investig 2000;2: 179-82.

37. Bhandari M, Adili A, Lachowski RJ. High pressure pulsatile lavage of contaminated human tibiae: an in vitro study. J Orthop Trauma 1998;12:479-84.

38. Bhandari M, Schemitsch EH. Highpressure irrigation increases adipocyte-like cells at the expense of osteoblasts in vitro. J Bone Joint Surg Br 2002;84:1054-61.

39. Owens BD, White DW, Wenke JC. Comparison of irrigation solutions and devices in a contaminated musculoskeletal wound survival model. J Bone Joint Surg Am 2009;91:92-8.

40. Penn-Barwell JG, Murray CK, Wenke JC. Comparison of the antimicrobial effect of chlorhexidine and saline for irrigating a contaminated open fracture model. J Orthop Trauma 2012;26:728-32.

41. Global status report on road safety: time for action. Geneva: World Health Organization, 2009 (http://www.who.int/ violence_injury_prevention/road_safety_ status/2009).

Copyright (c) 2015 Massachusetts Medical Society. 
Click here to confirm that you have read the article and receive Trauma Education Credit 